
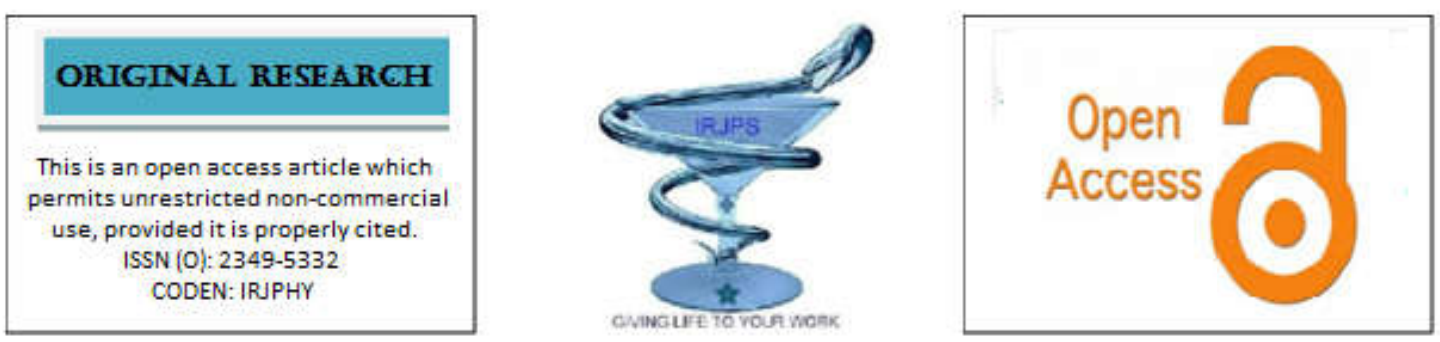

\title{
THE PRECIPITATING FACTOR OF DIABETIC KETOACIDOSIS FOR PATIENTS ADMITTED INTENSIVE CARE UNIT AT PRINCE RASHID HOSPITAL IN JORDAN.
}

\author{
Quteiba Nuseir, Sultan Almousa, Faraj Alhazaimeh, Moahad Al-Domi, Ra'fat Alhabashneh \\ Prince Rashid Hospital, Royal Medical Services, Jordan
}

Submitted on: 12.08.19;

Revised on: 26.08.19;

Accepted on: 30.08.19

\begin{abstract}
:
Introduction: Diabetic ketoacidosis (DKA) is a serious acute complications in diabetes patients. DKA increased mortality and morbidity rates. The main cause of DKA are noncompliance on insulin and infections.

Study objectives: The main objective of this study is to identify the main precipitating factors of DKA in hospitalization patients admitted to intensive care unit (ICU) in Jordan.
\end{abstract}

Methods and patients: A retrospective study design was conducted. A total of 150 files of patients with DKA were included. Files with complete information and data regarding DKA were included. Study variables included demographic variables such as age and gender; clinical presentations of patients with DKA such as abdominal pain, and polyuria; precipitating factors for DKA including infection and non-adherence to insulin treatment; and biochemical files of DKA patients including glucose level, creatinine, urea, and blood levels including hemoglobin and white blood cells. Data were analyzed using SPSS version 22.

Study results: Study findings showed that males were more likely to develop DKA, and age group under 20 years old were more prone to develop DKA. The most common clinical presentations included general body malaise, polydipsia 11, and polyuria. The most common precipitating factors for DKA includes non-adherence to insulin treatment and infections. Biochemical profile showed high level of glucose (570 $\pm 178 \mathrm{mg} / \mathrm{dl})$, and other parameters were consistent with DKA.

Conclusion: The findings of the present study confirmed the study hypothesis stating that the most precipitating factors of DKA patients in Jordan are non-adherence to insulin treatment and infections.

KEY WORDS: Diabetic Ketoacidosis, Precipitating Factors, Non-adherence Insulin

Corresponding author: Quteiba Nuseir

E-mail: quteiba_nuseir@yahoo.com

Mobile no: +962 777766267
Indian Research Journal of Pharmacy and Science; 22(2019)1926-1931;
Journal Home Page: https://www.irjps.in
DOI: 10.21276/irjps.2019.6.3.2 


\section{INTRODUCTION:}

Diabetic ketoacidosis (DKA) is a life threatening acute complications of type 1 diabetes mellitus $(\mathrm{T} 1 \mathrm{DM})^{1}$. Relatively or absolutely decreased level of insulin in T1DM shifts metabolism process in the body from primarily using glucose to using an alternative pathway for producing energy and the ketones derived from fatty acids make the blood more acidic and associated with serious consequences such as electrolyte disturbances and coma $^{2}$. DKA has been considered a serious acute complications that need to admit the patient into intensive care unit (ICU) for urgent treatment ${ }^{3}$. More than 500,000 patients per year are hospitalized with $\mathrm{DKA}^{4}$. However, studies have shown that the mortality rate of DKA has decreased from $7.96 \%$ to $0.67 \%$ in the last 20 years ${ }^{5}$; but the mortality rate in developing countries still high ${ }^{6}$.

American Diabetes Association (ADA) demonstrated that infections is the most common precipitating factor of $\mathrm{DKA}^{7}$. Other causes such as non-adherence on insulin therapy, myocardial infarction, stroke , alcohol consumption and pancreatitis are potential causes of $\mathrm{DKA}^{5,8-9}$. Moreover, previous studies have shown that both infections and non-adherence are the most precipitating factor of DKA ${ }^{6,10-11}$. Number of prevention strategies and education plans have been created to decrease the risk factors of DKA, for example ADA recommended to give influenza vaccination annually for diabetic patients with age $\geq$ 6 months to decrease the risk of respiratory infection which considered one of the most common cause of $\mathrm{DKA}^{12}$. However, many studies have shown that nonadherence on insulin therapy has been considered the main cause of DKA particularly in low-income countries $^{11,13-15}$. Based on the literature, the precipitating factors of DKA are different between countries and depend on number of variables such as age, climate, education level and economic level ${ }^{6,13 \text {, }}$ 16.
Hospitalization and management of DKA have very high costs on both public and private health insurance $^{6,13,17}$. In US hospitals, the annual cost of DKA was estimated about 2.4 billion dollars ${ }^{18}$. Accordingly, it is very important to identify the main precipitating factors of DKA to develop the key prevention strategies for DKA which will contribute in decreasing the health public costs. In Jordan, rare studies identified the most common precipitating factors of DKA. This study aims to investigate the precipitating factors of DKA in patients admitted to ICU at PRH, North of Jordan.

\section{Project Goals and Objectives:}

Our study aimed to identify the precipitating factors of diabetic ketoacidosis (DKA) in patients who admitted to intensive care unit (ICU) in Prince Rashid Hospital at Jordan. We planned to test our hypothesis to accomplish the overall objective of this study by pursuing study hypothesis:

Our hypothesis: non-adeherence on insulin therapy is the most common precipitating factor of DKA in patients who admitted to ICU in Prince Rashid Hospital at Jordan.

\section{Significance of Work:}

This study evaluated the potential precipitating factors of DKA in patients who admitted to ICU in Prince Rashid Hospital at north of Jordan. Therefore, this study could be the first step toward recommending and encouraging of health care providers, health care agencies and policy makers in Jordan to developed the appropriate DKA prevention strategies and the key education programs which will help in decreasing the cost of hospitalization of DKA and increased the awareness for all Jordanian patients.

\section{METHODOLOGY:}

\section{Subjects:}

All patients admitted to ICU complained from DKA in type 1 diabetes were included in the study, regardless of age. Medical records and history of 
illness of the patients were retrospectively reviewed. Patients were included if diagnosed as type 1 diabetes and had the DKA diagnosis criteria as the following: blood glucose $>250 \mathrm{mg} / \mathrm{dl}$ metabolic acidosis with arterial $\mathrm{pH}<7.30$ or serum bicarbonate $<18 \mathrm{mmol}$ and positive ketone body in serum or/and urine. The patients who have positive ketone for reason other than DKA, and with diagnosis other than DKA were excluded from the study.

\section{MATERIAL AND METHODS:}

The study was conducted in patients with DKA who admitted to Intensive Care Unit (ICU) at a Prince Rashid Hospital in the North of Jordan. Demographic Data including (age, and gender) were collected by reviewing medical records. The history data of the patients who admitted to ICU as DKA case were also taken. All the data were taken by the physician from the patients or their relatives at ICU. Vital signs and lab tests were recorded when the patients arrived the emergency room including: blood glucose, serum creatinine, level of potassium, ketones in serum and urine, and other diagnostic tests that were performed to investigate the precipitating factors, such as chest X-ray, urine and blood culture, ECG and troponin and CPK level. The precipitating factor of DKA were identified by emergency physician or endocrinologist evaluations. Non-adherence on treatment was determined the precipitating factor if the patients noncompliance on diet or insulin without finding infection and excluded other causes such as ischemic heart disease (IHD). Respiratory tract infection were revealed based on clinical signs and symptoms(e.g cough, expectoration, color of sputum, chest pain and crackles), chest-x ray and the physician investigation. Additionally, urinary tract infection were identified by urine analysis and urine culture. Ischemic heart disease was detected using ECG, troponin and CPK level. Other causes such as stroke, pancreatitis, gastrointestinal infection and other type of infection were also investigated and identified by emergency physician evaluation.

\section{STATISTICAL ANALYSIS:}

Data will be described total number of patients as percentages (\%) for categorical data, means \pm Standard deviation (SD) for continuous variables. Analysis was performed using SPSS 22.0.

\section{RESULTS:}

As shown in table 1, the study included 93 (62\%) males and $57(38 \%)$ females. About $75 \%$ of participants were $\leq 20$ years old.

Table 1: Demographic characteristics of participants

\begin{tabular}{|c|c|c|}
\hline Variable & Frequency (N) & Percentage (\%) \\
\hline Gender: & & \\
\hline - $\quad$ Males & 93 & $62 \%$ \\
\hline - $\quad$ Females & 57 & $38 \%$ \\
\hline Age (years): & & \\
\hline$-\leq 20$ & 113 & $75.33 \%$ \\
\hline$->20$ & 37 & $24.66 \%$ \\
\hline
\end{tabular}

\section{Clinical presentations associated with DKA patients}

As demonstrated in table 2, abdominal pain was reported in $14 \%$ of cases. Blurred vision was reported in approximately $3 \%$ of cases. Coma was reported by about $5 \%$ of cases. A total of 12 cases (8\%) reported confusion. About $41 \%$ of DKA patients experienced general body malaise. 
Kussmaul's breathing was shown in approximately $11 \%$ of patients. A total of $57(38 \%)$ patients experienced loss of consciousness. Nausea was reported in approximately $7 \%$ of patients. Polydipsia 11 was experienced by approximately $43 \%$ of patients, polyphagia by $8 \%$ of patients, and polyuria was experienced by about $41 \%$ of cases. Vomiting was reported by $22 \%$ of cases, and weight loss was shown by $8 \%$ of cases.

Table 2: Clinical presentations associated with DKA patients $(n=150)$

\begin{tabular}{|l|c|c|}
\hline \multicolumn{1}{|c|}{ Variable } & Frequency (N) & Percentage (\%) \\
\hline Abdominal pain & 21 & $14 \%$ \\
\hline Blurred vision & 4 & $2.67 \%$ \\
\hline Coma & 7 & $4.67 \%$ \\
\hline Confusion & 12 & $8 \%$ \\
\hline General body malaise & 62 & $41.33 \%$ \\
\hline Kussmaul's breathing & 17 & $11.33 \%$ \\
\hline Loss of consciousness & 57 & $38 \%$ \\
\hline Nausea & 11 & $7.33 \%$ \\
\hline Polydipsia ll & 64 & $42.64 \%$ \\
\hline Polyphagia & 12 & $8 \%$ \\
\hline Polyuria & 62 & $41.33 \%$ \\
\hline Vomiting & 33 & $22 \%$ \\
\hline Weight loss & 12 & $8 \%$ \\
\hline
\end{tabular}

\section{Precipitating factors for DKA $(\mathrm{N}=150)$}

The study results revealed several precipitating factors for DKA patients. Missed insulin injection (nonadherence to insulin treatment) ranked the first precipitating factor DKA (58\%) among study participants. Infection was the second precipitating factor for DKA patients (56\%). The third precipitating factor was co-morbidity (approximately 25\%). Stroke, as a precipitating factor for DKA, was experienced by approximately $17 \%$ and ranked fourth. Hypertension was shown among approximately $5 \%$ of cases, and chronic renal failure was also shown in approximately $5 \%$ of cases.

Table 3: Precipitating factors for DKA $(\mathrm{N}=150)$

\begin{tabular}{|l|c|c|}
\hline \multicolumn{1}{|c|}{ Variable } & Frequency (N) & Percentage (\%) \\
\hline Infection & 84 & $56 \%$ \\
\hline Missed insulin injection & 87 & $58 \%$ \\
\hline Co-morbidity & 38 & $25.33 \%$ \\
\hline Stroke & 26 & $17.33 \%$ \\
\hline Chronic renal failure & 7 & $4.66 \%$ \\
\hline Hypertension & 8 & $5.33 \%$ \\
\hline
\end{tabular}




\section{Biochemical findings of DKA patients}

As demonstrated in table 4, glucose level was 570 $\pm 178 \mathrm{mg} / \mathrm{dl}$. The mean urea was $59 \pm 31 \mathrm{mg} / \mathrm{dl}$. The mean creatinine was $1.22 \pm 0.7 \mathrm{mg} / \mathrm{dl}$. Troponin mean was $7.5 \pm 6.3 \mathrm{ng} / \mathrm{dl}$. The mean of white blood cells was $15.1 \pm 710^{3} / \mathrm{ml}$. hemoglobin mean was $14.6 \pm 1.8$ $\mathrm{g} / \mathrm{dl}$. Systolic blood pressure level was $122 \pm 25$ $\mathrm{mmHg}$. The mean of potassium was $42 \pm 28.3$ $(\mathrm{mEq} / \mathrm{l}) \%$. The level of magnesium was $28.5 \pm 22.6$ $\mathrm{mg} / \mathrm{dl}$. The mean of phosphate was $74 \pm 63.2 \mathrm{mg} / \mathrm{dl}$.

Table 4: Biochemical findings of DKA patients

\begin{tabular}{|l|c|c|}
\hline \multicolumn{1}{|c|}{ Variable } & Mean & Standard deviation (SD) \\
\hline Glucose $(\mathrm{mg} / \mathrm{dl})$ & 570 & 178 \\
\hline Urea $(\mathrm{mg} / \mathrm{dl})$ & 59 & 31 \\
\hline Creatinine $(\mathrm{mg} / \mathrm{dl})$ & 1.22 & 0.7 \\
\hline Troponin $(\mathrm{ng} / \mathrm{ml})$ & 7.5 & 6.3 \\
\hline White blood cells $\left(10^{3} / \mathrm{ml}\right)$ & 15.1 & 1.8 \\
\hline Hemoglobin $(\mathrm{g} / \mathrm{dl})$ & 14.6 & 25 \\
\hline Systolic blood pressure $(\mathrm{mm} \mathrm{Hg})$ & 122 & 28.3 \\
\hline Potassium $(\mathrm{mEq} / \mathrm{l}) \%$ & 42 & 22.6 \\
\hline Magnesium $(\mathrm{mg} / \mathrm{dl})$ & 28.5 & 63.2 \\
\hline Phosphate $(\mathrm{mg} / \mathrm{dl})$ & 74 & \\
\hline
\end{tabular}

\section{DISCUSSION:}

The present study was conducted to investigate various aspects of DKA associated with type 1 diabetes. The results of this study revealed the occurrence of DKA to be more likely among males, and among subjects $\leq 20$ years. This is in line with other studies that reported the incidence of T1D to be 1.5 times higher in males than in females, and less in subjects under 40 years of age ${ }^{19,20}$.

The results of the present study showed that the most occurred clinical presentations in patients with DKA included polydipsia $11(43 \%)$, general body malaise (41\%), and polyuria (41\%). Similar trends were reported $^{21-23}$.

The results of this data showed that the most precipitating factors for DKA patients are missed insulin injection (58\%), and infection 56\%. These results agree with previous studies that put focus on infection and non-adherence to insulin therapy $5,7,8,11$, 13-15. These findings confirm our hypothesis that nonadherence to insulin therapy and infections are the most precipitating factors for DKA patients in Jordan.
The results of the present study showed that biochemical profile of patients with PKA in Jordan represent DKA with moderate severity and these findings are consistent with international findings reported in different studies $2,3,5,8,10,12,14$.

\section{CONCLUSIONS:}

The findings of the present study confirmed the study hypothesis stating that the most precipitating factors of DKA patients in Jordan are non-adherence to insulin treatment and infections.

\section{REFERENCES:}

1. Kerner W, Initiative D. Event Rates and Risk Factors for the Development of Diabetic Ketoacidosis in Adult Patients With Type 1 Diabetes: Analysis From the DPV Registry Based on 46,966 Patients. 2019.

2. Kanikarla-Marie P, Jain SK. Hyperketonemia and ketosis increase the risk of complications in type 1 diabetes. Free Radical Biology and Medicine. 2016;95:268-77.

3. Gershengorn HB, Iwashyna TJ, Cooke CR, Scales DC, Kahn JM, Wunsch H. Variation in use of intensive care for adults with diabetic ketoacidosis. Critical care medicine. 2012;40(7):2009.

4. Statistics NCfH. National hospital discharge and ambulatory surgery data [article online]. Diakses 
dari: http://www cde gov/nchs/about/major/hdasd/nhds htm. 2009.

5. Umpierrez G, Korytkowski M. Diabetic emergencies-ketoacidosis, hyperglycaemic hyperosmolar state and hypoglycaemia. Nature reviews Endocrinology. 2016;12(4):222.

6. Alourfi Z, Homsi H. Precipitating factors, outcomes, and recurrence of diabetic ketoacidosis at a university hospital in Damascus. Avicenna journal of medicine. 2015;5(1):11.

7. Rahim MA, Rouf R, Ahmed AU, Uddin KN, Latif ZA. Pattern of Precipitating Causes of Diabetic Ketoacidosis in A Tertiary Care Hospital of Bangladesh. Bangladesh Journal of Medicine. 2018;29(1):3-6.

8. Ko SH, Lee WY, Lee JH, Kwon HS, Lee JM, Kim SR, et al. Clinical characteristics of diabetic ketoacidosis in Korea over the past two decades. Diabetic medicine. 2005;22(4):466-9.

9. Zhong VW, Juhaeri J, Mayer-Davis EJ. Trends in hospital admission for diabetic ketoacidosis in adults with type 1 and type 2 diabetes in England, 1998-2013: a retrospective cohort study. Diabetes care. 2018;41(9):1870-7.

10. Anupama B, Chandrasekhara P, Krishnamurthy M, Aslam M. Clinical and laboratory profile of diabetic ketoacidosis in elderly with type 2 diabetes mellitus. BLDE University Journal of Health Sciences. 2018;3(2):79.

11. Del Degan S, Dubé F, Gagnon C, Boulet G. Risk Factors Of Recurrent Diabetic Ketoacidosis In Adults With Type 1 Diabetes. Canadian Journal of Diabetes. 2019.

12. Chiang JL, Maahs DM, Garvey KC, Hood KK, Laffel LM, Weinzimer SA, et al. Type 1 diabetes in children and adolescents: a position statement by the American Diabetes Association. Diabetes care. 2018;41(9):2026-44.

13. Maldonado MR, Chong ER, Oehl MA, Balasubramanyam A. Economic impact of diabetic ketoacidosis in a multiethnic indigent population: analysis of costs based on the precipitating cause. Diabetes care. 2003;26(4):1265-9.
14. Alkhiari R, Alzayer $\mathrm{H}$, Aljazeeri J, Vanniyasingam T, Punthakee $\mathrm{Z}$. Adherence to Guidelines for Inpatient Pharmacologic Management of Type 2 Diabetes in Adults and Glycemic Outcomes. Canadian Journal of Diabetes. 2018;42(2):158-62.

15. Bourdages M, Barbe J, Cloutier D, Bouchard I, Gagné J. ADHERENCE TO DIABETIC KETOACIDOSIS MANAGEMENT PROTOCOL: A PAEDIATRIC CENTRE EXPERIENCE. Paediatrics \& Child Health. 2016;21(5):E71.

16. Lontchi-Yimagou E, Tsalefac M, Tapinmene LMT, Noubiap JJN, Balti EV, Nguewa J-L, et al. Seasonality in diabetes in Yaounde, Cameroon: a relation with precipitation and temperature. BMC public health. 2016;16(1):470.

17. Barranco R, Gomez-Peralta F, Abreu C, Delgado-Rodriguez M, Moreno-Carazo A, Romero F, et al. Incidence, recurrence and cost of hyperglycaemic crises requiring emergency treatment in Andalusia, Spain. Diabetic medicine. 2017;34(7):966-72.

18. Weinert LS, Scheffel RS, Severo MD, Cioffi AP, Teló GH, Boschi A, et al. Precipitating factors of diabetic ketoacidosis at a public hospital in a middleincome country. Diabetes research and clinical practice. 2012;96(1):29-34.

19. Diaz-Valencia PA, Bougnères $P$, Valleron AJ. Global epidemiology of type 1 diabetes in young adults and adults: a systematic review. BMC Public Health 2015;15:255.

20. Weinstock RS, Xing D, Maahs DM, et al. Severe hypoglycemia and diabetic ketoacidosis in adults with type 1 diabetes: results from the T1D Exchange clinic registry. J Clin Endocrinol Metab 2013;98:3411-9.

21. Pankaj Seth, Harpreet Kaur, Maneet Kaur. Clinical Profile of Diabetic Ketoacidosis: A Prospective Study in a Tertiary Care Hospital. Journal of Clinical and Diagnostic Research, 2015, 9(6): OC01-OC04.

22. Adhikari PM, Mohammed N, Pereira P. Changing profile of diabetic ketosis. J Indian Med Assoc. 1997;95(10): 540-42.

23. Umpierrez G, Freire AX. Abdominal pain in patients with hyperglycaemic crises. J Crit Care. 2002; 17:63-67. 